\title{
Use of potassium chloride for low-residue euthanasia of anesthetized California sea lions (Zalophus californianus) and northern elephant seals (Mirounga angustirostris) with life-threatening injury or disease
}

\author{
Emily R. Whitmer DVM \\ Emily J. Trumbull DVM \\ Heather S. Harris DVM, MPVM \\ Sophie T. Whoriskey DVM \\ Cara L. Field DVM, PhD \\ From The Marine Mammal Center, Sausalito, CA 94965. \\ Address correspondence to Dr. Whitmer (emily.whitmer@ \\ gmail.com).
}

\begin{abstract}
OBJECTIVE
To demonstrate the efficacy of potassium chloride $(\mathrm{KCl})$ for low-residue euthanasia of anesthetized pinnipeds in field settings for which carcass retrieval for disposal is not feasible.
\end{abstract}

\begin{abstract}
ANIMALS
Stranded, free-ranging California sea lions (CSLs; Zalophus californianus; $\mathrm{n}=$ 17) and northern elephant seals (NESs; Mirounga angustirostris; 6) with lifethreatening injury or disease between May and August 2020.
\end{abstract}

\section{PROCEDURES}

Each animal was anesthetized and then received a lethal dose of $\mathrm{KCl}$ solution administered by IV or intracardiac injection. The effective $\mathrm{KCl}$ dose; durations to cardiac arrest, respiratory arrest, and pupil dilation; and presence or absence of agonal breaths, muscle fasciculations, or skeletal movements were recorded.

\begin{abstract}
RESULTS
Mean effective dose of $\mathrm{KCl}$ was $207.4 \mathrm{mg} / \mathrm{kg}(94.3 \mathrm{mg} / \mathrm{lb})$ for the $17 \mathrm{CSLs}$ and $209.1 \mathrm{mg} / \mathrm{kg}(95.0 \mathrm{mg} / \mathrm{lb})$ for 5 of 6 NESs (I outlier NES was excluded). The range in duration from the beginning of $\mathrm{KCl}$ injection to cardiac arrest was 0 to 6 minutes, to pupil dilation was 0 to 5 minutes, and to respiratory arrest was 0 to 5 minutes. Muscle fasciculations, skeletal movements, and agonal breaths were observed in both species during and after $\mathrm{KCl}$ administration.
\end{abstract}

\section{CONCLUSIONS AND CLINICAL RELEVANCE}

The use of $\mathrm{KCl}$ provides an effective, low-residue method of euthanasia in anesthetized CSLs and NESs. Our recommended dose for these species is $250 \mathrm{mg} \mathrm{KCl} / \mathrm{kg}$ (II3.6 mg KCl/lb) delivered by intracardiac injection. Compared with euthanasia by barbiturate overdose, the use of $\mathrm{KCl}$ reduces the potential for secondary intoxication of scavengers and is appropriate in field scenarios in which the carcass cannot be retrieved for disposal. ( $\mathrm{Am}$ Vet Med Assoc 2021;259:197-20I)
$\mathbf{T}$ he need for field euthanasia of pinnipeds occasionally arises for circumstances in which carcass retrieval for disposal is logistically challenging to impossible. This could include mass stranding events, remote field research, or carcasses that are too large for removal given the terrain, available equipment, or personnel. For these instances in which the carcass will be left in situ, common methods of euthanasia by anesthetic (eg, barbiturate) overdose may result in drug residues in tissues that pose secondary intoxication risk to scavengers, including domestic and wild animals. ${ }^{1}$ Therefore, methods of low-residue euthanasia that pose minimal risk of toxicoses in scavengers and drug contamination to the environment are required. ${ }^{2}$

$\begin{array}{ll}\text { ABBREVIATIONS } \\ \text { CSL } & \text { California sea lion } \\ \text { IC } & \text { Intracardiac } \\ \mathrm{KCl} & \text { Potassium chloride } \\ \text { NES } & \text { Northern elephant seal } \\ \text { TMMC } & \text { The Marine Mammal Center }\end{array}$

Administration of a lethal dose of $\mathrm{KCl}$ solution to an animal at a surgical plane of general anesthesia is an accepted method of euthanasia. ${ }^{3} \mathrm{~A}$ high serum potassium concentration suppresses myocardial electrical conduction, leading to arrhythmias. ${ }^{4,5}$ At sufficient doses, rapid IC or IV administration of potassium results in cardiac arrest. It is generally accepted that the $\mathrm{KCl}$ in tissues following euthanasia does not pose an intoxication risk to scavengers. ${ }^{3,6}$ Additional potential benefits include that $\mathrm{KCl}$ is inexpensive, readily acquired and transported, and not a controlled drug.

Potassium chloride is a recognized euthanasia agent in anesthetized cattle ${ }^{7}$ and other domestic large animals. ${ }^{3}$ It has been evaluated for efficacy in mice, ${ }^{8}$ koi, ${ }^{9}$ psittacines, ${ }^{10}$ moon jellyfish, ${ }^{11}$ American lobsters, ${ }^{12}$ and giant cockroaches. ${ }^{13}$ Lethal administration of $\mathrm{KCl}$ after anesthesia is recommended by the National Oceanic and Atmospheric Administration for euthanasia of stranded cetaceans in some circumstances, ${ }^{14}$ has been described for euthanasia of large cetaceans, ${ }^{6,15}$ and is an accepted protocol for euthanasia at TMMC. ${ }^{3,16} \mathrm{Al}-$ though the use of $\mathrm{KCl}$ solution is occasionally listed by 
researchers in proposals and permits as the planned method of euthanasia for pinnipeds should the need arise in the course of field research, there is only limited general information on the use of $\mathrm{KCl}$ for euthanasia of pinnipeds. ${ }^{16}$ The objectives of the study reported here were to demonstrate the efficacy of the use of $\mathrm{KCl}$ solution for euthanasia in anesthetized CSLs (Zalopbus californianus) and NESs (Mirounga angustirostris), describe the type and frequency of observed physical signs in the animals during euthanasia with $\mathrm{KCl}$ solution, and discuss logistic considerations for this method of euthanasia.

\section{Materials and Methods}

\section{Animals}

All animals were free-ranging pinnipeds that had stranded along the California coastline and had been brought to TMMC for assessment and possible rehabilitation in accordance with a Stranding Agreement with the National Oceanic and Atmospheric Administration, National Marine Fisheries Service, West Coast Region. All procedures were performed at TMMC veterinary hospital. Species, sex, and age class were determined during admission examination within 24 to 72 hours after stranding. The age classes for CSLs were pup, yearling, juvenile, subadult, and adult on the basis of age-range standards for tooth eruption and straight total body length, measured from nose to tail. ${ }^{17}$ The age classes of NESs were pup, yearling, juvenile, and adult on the basis of age-range standards for body weight, tooth eruption, and pelage condition. ${ }^{18,19}$

\section{Euthanasia}

KCl solution-The $\mathrm{KCl}$ solution was prepared with $300 \mathrm{~g}$ of $\mathrm{KCl}$ powder ${ }^{\mathrm{a}}$ and room temperature tap water at a quantity sufficient to generate $1 \mathrm{~L}$ of solution, which was then shaken vigorously until all of the $\mathrm{KCl}$ powder dissolved. The resulting solution contained approximately $300 \mathrm{mg} \mathrm{KCl} / \mathrm{mL}\left(4 \mathrm{mmol} \mathrm{K} \mathrm{K}^{+}\right.$) $\mathrm{mL} ; 4 \mathrm{mEq} \mathrm{K}^{+} / \mathrm{mL}$ ) and was stored in a clearly labeled, nonsterile, screw-top, wide-mouth plastic bottle. The maximum duration of storage from preparation to administration was 78 days.

Criteria-For each animal, euthanasia was ordered by the attending clinician on the basis of individual need and in accordance with TMMC protocols for medical care of stranded marine mammals and standards practiced by members of the National Marine Fisheries Service's Marine Mammal Health and Stranding Response program. Criteria for euthanasia included injury or disease from which there was no reasonable expectation of recovery or permanent impairment of a function required for the animal's survival in its natural environment with no option for long-term captive placement. Observational data were collected opportunistically in the course of routine veterinary care in accordance with facility euthanasia protocols.
Anesthesia-All animals received anesthetic drugs (injectable, inhalant, or both) prior to euthanasia. ${ }^{20}$ All animals were at a surgical plane of anesthesia as assessed by eye position, muscle tone, palpebral and corneal reflexes, and response to noxious stimulus (ie, phlebotomy or strong digit pinch with a hemostat). Anesthetic protocol selection was based on the individual animal's health status and need for chemical restraint, physical examination, diagnostic imaging, or other diagnostic procedures, alone or in combination. For some animals, anesthesia was ordered specifically for the purpose of euthanasia, whereas for other animals, the clinical decision to euthanize rather than to recover from anesthesia was made during an anesthetic procedure.

Procedure-Potassium chloride solution was administered by IC or IV injection. Venous access was achieved in CSLs through the subclavian vein with the animal in dorsal recumbency and in NESs through the epidural sinus with the animal in ventral recumbency. ${ }^{21}$ In both species, IC injection was achieved with the animal in dorsal recumbency. The cardiac point of maximum intensity (typically between the sixth and seventh or between the seventh and eighth ribs) was palpated on the ventral aspect of the midregion of the thorax, and the needle was inserted through the intercostal muscles just lateral to either side of the sternum. In all methods, blood was aspirated to confirm proper needle placement. Sixteen- or 18-gauge needles were used. Needle lengths were 3.8 to $5.1 \mathrm{~cm}$ (1.5 to 2 inches) for all IV injections and for IC injection in animals weighing approximately $\leq 30 \mathrm{~kg}$ (66 lb), whereas needles $7.6 \mathrm{~cm}$ ( 3 inches) in length with a stylet were used in animals $>30 \mathrm{~kg}$. For each animal, the prepared dose of $\mathrm{KCl}$ solution was $200 \mathrm{mg} \mathrm{KCl} / \mathrm{kg}(90.1 \mathrm{mg} \mathrm{KCl} / \mathrm{lb}$; $2.67 \mathrm{mmol} \mathrm{K} / \mathrm{kg}$ [1.21 mmol/lb]; $2.67 \mathrm{mEq} \mathrm{K} / \mathrm{kg}$ ); however, the actual amount administered varied by animal and clinician. The total administered dose of $\mathrm{KCl}$ was recorded for each animal. If cardiac arrest occurred during administration of the $\mathrm{KCl}$ solution, the dose administered to the point of cardiac arrest was recorded as the effective dose.

The durations in minutes from the onset of $\mathrm{KCl}$ solution administration to cardiac arrest, respiratory arrest, and pupil dilation were recorded. Pupil dilation was used as an approximate indicator of brain death. ${ }^{22,23}$ Each animal was observed for physical signs during and after administration of the $\mathrm{KCl}$ dose. The presence or absence of muscle fasciculations, muscle contractions resulting in skeletal movements, or agonal breaths was recorded. A gross postmortem examination was performed on each animal by an experienced technician or veterinarian under the supervision of a veterinary pathologist. Histologic examinations were not performed.

\section{Statistical analysis}

Results were reported as the number of affected animals and as the means, 95\% CIs, medians, and 
ranges of variables of interest. All calculations were performed with available software. ${ }^{\mathrm{b}}$

\section{Results}

\section{Animals}

There were 17 CSLs and 6 NESs euthanized between May and August 2020 included in the study, and data from each animal were compiled (Supplementary Table SI, available at: avmajournals.avma. org/doi/suppl/10.2460/javma.259.2.197). The CSLs consisted of 2 pups ( 1 male and 1 female), 2 yearlings (both females), 5 juveniles (all males), 4 subadults ( 3 males and 1 female), and 4 adults (1 male and 3 females), with a median body weight of $47.5 \mathrm{~kg}$ (104.5 lb; range, 11.5 to $149.0 \mathrm{~kg}$ [ 25.3 to $327.8 \mathrm{lb}$ ]). All NESs were weaned pups ( 2 males and 4 females) with a median body weight of $41.5 \mathrm{~kg}$ ( $91.3 \mathrm{lb}$; range, 38.0 to $46.0 \mathrm{~kg}$ [83.6 to $101.2 \mathrm{lb}]$ ). The most common reasons for euthanasia were neurologic disease $(n=8)$, trauma (7), or severe malnutrition with various comorbidities (4). All animals with neurologic disease were CSLs that had seizure-like activity, neurologic deficits, or behavioral abnormalities, alone or in combination, suggestive of domoic acid intoxication. ${ }^{24}$

\section{Euthanasia}

Anesthesia-Most of the CSLs received tiletaminezolazepam $^{\mathrm{c}}$ alone administered IM $(\mathrm{n}=10)$ or tiletamine-zolazepam and lorazepam administered IM (2). Five CSLs received other IM injectable formulations of induction agents (alfaxalone, butorphanol, dexmedetomidine, medetomidine, or midazolam, alone or in combination) followed by administration of isoflurane in oxygen delivered by face mask $(n=4)$ or endotracheal tube (1; Supplementary Table S2, available at: avmajournals.avma.org/doi/suppl/10.2460/ javma.259.2.197). All NESs were anesthetized with IM administration of tiletamine-zolazepam alone. Before administration of $\mathrm{KCl}$, each animal was determined to have been at a deep or surgical plane of anesthesia on the basis of absent voluntary movement, marked skeletal muscle relaxation, absent palpebral reflex, ventromedial or central position of the eyes, and absent response to noxious stimulus.

Mean effective dose of $\mathrm{KCl}$-Potassium chloride solution was administered by IC injection to 15 CSLs and by IV injection to 2 CSLs (Supplementary Table S1). For CSLs, the mean effective dose (IC or IV) of $\mathrm{KCl}$ was $207.4 \mathrm{mg} / \mathrm{kg}$ (94.3 mg/lb; 95\% CI, 166.4 to $248.4 \mathrm{mg} / \mathrm{kg}$ [75.6 to $112.9 \mathrm{mg} / \mathrm{lb}$ ]; median, 200.0 $\mathrm{mg} / \mathrm{kg}[90.9 \mathrm{mg} / \mathrm{lb}]$; range, 45.2 to $391.3 \mathrm{mg} / \mathrm{kg}[20.5$ to $177.9 \mathrm{mg} / \mathrm{lb}])$. The mean effective dose of $\mathrm{KCl}$ was similar among animals grouped on the basis of anesthetic protocol $(200.9 \mathrm{mg} / \mathrm{kg}$ [91.3 $\mathrm{mg} / \mathrm{lb}]$ for the 10 CSLs that received tiletamine-zolazepam alone, 184 $\mathrm{mg} / \mathrm{kg}[83.6 \mathrm{mg} / \mathrm{lb}]$ for the 2 that received tiletaminezolazepam and lorazepam, and $222.2 \mathrm{mg} / \mathrm{kg}[101.0$ $\mathrm{mg} / \mathrm{lb}$ ] for the 5 that received isoflurane). Mean effective dose of $\mathrm{KCl}$ by IC injection $(\mathrm{n}=15)$ was 206.9 $\mathrm{mg} / \mathrm{kg}$ (94 mg/lb; 95\% CI, 160.3 to $253.5 \mathrm{mg} / \mathrm{kg}$ [72.9 to $115.2 \mathrm{mg} / \mathrm{lb}])$. The remaining $2 \mathrm{CSLs}$ received IV injections, and their effective doses were 189.5 and $167.8 \mathrm{mg} / \mathrm{kg}$ (86.1 and $76.3 \mathrm{mg} / \mathrm{lb})$.

Potassium chloride solution was administered by IC injection to 3 NESs and by IV injection to 3 NESs. For NESs, the mean effective dose of $\mathrm{KCl}$ was 253.5 $\mathrm{mg} / \mathrm{kg}$ (115.2 mg/lb; 95\% CI, 164.3 to $342.9 \mathrm{mg} / \mathrm{kg}$ [74.7 to $155.9 \mathrm{mg} / \mathrm{lb}$ ]; median, $218.3 \mathrm{mg} / \mathrm{kg}$ [99.2 mg/ lb]; range, 163.0 to $284.4 \mathrm{mg} / \mathrm{kg}$ [ 74.1 to $216.2 \mathrm{mg} / \mathrm{lb}])$. An apparent outlier (individual $\mathrm{W}$ in Supplementary Table S1) received an initial dose of $\mathrm{KCl}(220 \mathrm{mg} / \mathrm{kg}$ [100 $\mathrm{mg} / \mathrm{lb}]$, IV in the epidural sinus), and yet the heart was still beating 3 minutes later. Thus, a second dose of $\mathrm{KCl}$ (256 mg/kg [116 mg/lb], IV in the epidural sinus) was administered; cardiac arrest occurred 3 minutes later. When data for this NES were excluded from the data set, the mean effective dose of $\mathrm{KCl}$ in the remaining NESs was $209.1 \mathrm{mg} / \mathrm{kg}$ (95.0 mg/lb; 95\% CI, 184.7 to $233.5 \mathrm{mg} / \mathrm{kg}$ [84.0 to $106.1 \mathrm{mg} / \mathrm{lb}$ ]); $\mathrm{n}=5$ ).

Clinical signs-Muscle fasciculations were observed during or after $\mathrm{KCl}$ administration in 4 of the 17 CSLs and 4 of the 6 NESs (Supplementary Table S1). All 4 of the CSLs that had muscle fasciculations had been anesthetized with tiletamine-zolazepam alone $(n=3)$ or tiletamine-zolazepam and lorazepam (1). Muscle fasciculations were not observed in any CSLs that received inhalant anesthetic prior to euthanasia. One CSL, a juvenile male with trauma but no clinical history of neurologic disease, exhibited tremors and muscle fasciculations suggestive of a seizure that started after tiletamine-zolazepam administration and continued during $\mathrm{KCl}$ administration. Large muscle contractions, including arching of the neck, movement and rigidity of the limbs, or both occurred during or after $\mathrm{KCl}$ administration in 1 NES and 6 CSLs and occurred regardless of anesthetic protocol. Agonal breaths, with or without exaggerated thoracic excursion, were observed during or after $\mathrm{KCl}$ administration in 3 of the 6 NESs and in 7 of the 17 of CSLs and occurred regardless of anesthetic protocol. Similarly, observed physical signs occurred fairly evenly in pinnipeds grouped by reason for euthanasia.

Data for the duration from the start of administration of $\mathrm{KCl}$ to cardiac arrest, pupil dilation, and respiratory arrest were compiled (Supplementary Table S1). Results for $\geq 1$ of these variables were not available for 5 CSLs and 2 NESs. For CSLs, the mean duration from the start of $\mathrm{KCl}$ administration to cardiac arrest was 0.8 minutes (range, 0 to 1 minute; $\mathrm{n}=13$ ), to pupil dilation was 2 minutes (range, 0 to 4 minutes; 14), and to respiratory arrest was 1.5 minutes (range, 0 to 4 minutes; 13 ). The means and ranges were similar among animals grouped on the basis of anesthetic combinations administered. For NESs, the mean duration from the start of $\mathrm{KCl}$ administration to cardiac arrest was 2 minutes (range, 0 to 6 minutes; $n=5$ ), to pupil dilation was 3.5 minutes (range, 1 to 5 minutes; 4 ), and to respiratory arrest was 2 minutes (range, 0 to 5 minutes; 5 ). 
No postmortem artifacts attributed to $\mathrm{KCl}$ administration were found in any of the animals on gross necropsy. Further, written necropsy reports were reviewed retrospectively by a single examiner (ERW), and no common gross features were found that could have been attributed to $\mathrm{KCl}$.

\section{Discussion}

The $\mathrm{KCl}$ dose administered ranged widely for the CSLs (45.2 to $391.3 \mathrm{mg} / \mathrm{kg}$ ) and NESs (163.0 to 475.6 $\mathrm{mg} / \mathrm{kg}$ [74.1 to $216.2 \mathrm{mg} / \mathrm{lb}])$ in the present study. On the basis of the upper limit of the $95 \%$ CI for the effective dose of $\mathrm{KCl}$ for the CSLs $(248.4 \mathrm{mg} / \mathrm{kg})$ and NESs without the apparent outlier $(233.5 \mathrm{mg} / \mathrm{kg})$, we rounded both for a suggested clinically useful dose of $250 \mathrm{mg}$ $\mathrm{KCl} / \mathrm{kg}(113.6 \mathrm{mg} \mathrm{KCl} / \mathrm{lb} ; 3.3 \mathrm{mmol} \mathrm{K} / \mathrm{kg}[1.5 \mathrm{mmol} \mathrm{K}+$ $\mathrm{lb}] ; 3.3 \mathrm{mEq} \mathrm{K} / \mathrm{kg}$ ) to be administered IC for euthanasia of anesthetized, debilitated CSLs and NESs. This dose is higher than the lethal dose of 75 to $150 \mathrm{mg} \mathrm{KCl} / \mathrm{kg} \mathrm{(34.1}$ to $68.2 \mathrm{mg} \mathrm{KCl} / \mathrm{lb}$ ) recommended across taxa. ${ }^{3}$ Louis et $\mathrm{al}^{9}$ showed that $10 \mathrm{mEq} \mathrm{K} / \mathrm{kg}(4.5 \mathrm{mEq} \mathrm{K} / \mathrm{lb})$ administered IC is lethal in anesthetized koi but did not evaluate lower doses. Similarly, Raghav et $\mathrm{al}^{10}$ indicated that a dose of 3 or $10 \mathrm{mEq} \mathrm{K} / \mathrm{kg}(1.4$ or $4.5 \mathrm{mEq} \mathrm{K} / \mathrm{lb})$ was effective for euthanasia in psittacine birds but that 10 $\mathrm{mEq} \mathrm{K}^{+} / \mathrm{kg}$ resulted in more rapid death.

Our findings indicated that IV administration of $\mathrm{KCl}$ solution into the epidural sinus of NESs was effective. However, 1 NES required 2 IV boluses of $\mathrm{KCl}$ to induce cardiac arrest; the initial dose was likely inadequately circulated to the heart. Given that phocids have high-volume venous blood storage capacity, such as in the hepatic and epidural sinuses and perirenal vasculature ${ }^{25}$ preparation for a higher $\mathrm{KCl}$ dose, fluid bolus after administration into the epidural sinus, or both is recommended. Results also indicated that subclavian vein IV administration of $\mathrm{KCl}$ solution was effective in CSLs. Higher doses or fluid bolus after administration would not likely be necessary because blood in the subclavian vein flows directly into the cranial vena cava, then the heart. ${ }^{21}$ Sample size for IV administration in CSLs and NESs was low; additional data are required to draw strong conclusions regarding the routes of IV administration of $\mathrm{KCl}$ used in the present study.

Individuals performing euthanasia by the administration of $\mathrm{KCl}$ solution should be aware of the range and duration of possible physical effects after administration. Skeletal muscle contractions have been reported during and after administration of $\mathrm{KCl}$ in other anesthetized species. ${ }^{3,7,10}$ Agonal breaths, muscle fasciculations, and large muscle contractions (eg, neck arching or appendicular skeletal rigidity) were common physical signs that occurred during $\mathrm{KCl}$ euthanasia of animals in the present study. These physical signs are within the range of accepted adverse effects for euthanasia given that all animals were assessed to have been at an appropriate plane of anesthesia. Physical signs may vary with different pre-euthanasia anesthetic protocols. For example, fasciculations and large muscle contractions were not observed in any of the 5 CSLs that received isoflurane; however, larger sample sizes are needed to confirm this finding. The frequent occurrence of agonal breaths, which occur as a result of brainstem hypoxia and are common following cardiac arrest, was expected because of the physiologic effects of $\mathrm{KCl}^{26,27}$

Other physical signs observed during $\mathrm{KCl}$ euthanasia may be unexpected and potentially alarming. Veterinary staff familiar with euthanasia of pinnipeds by pentobarbital overdose may be surprised by qualitative differences in physical signs between the 2 protocols. Therefore, advanced discussion of the protocol and range of possible physical signs is important for veterinary team members and any observers.

No gross postmortem artifacts attributed to the administration of $\mathrm{KCl}$ solution were detected in the animals of the present study. In other studies, postmortem gross and histologic artifacts caused by administration of $\mathrm{KCl}$ are reported to be subtle to absent. ${ }^{10,28,29}$ Raghav et $\mathrm{al}^{10}$ found no histologic artifacts in 12 psittacine birds euthanized with $\mathrm{KCl}$. Coulibaly et $\mathrm{al}^{27}$ identified whitish crystallized deposits on internal organs on gross examination and rare crystalline bundles on histologic examination of 2 human fetuses after medical termination of pregnancy with the use of $\mathrm{KCl}$.

Potassium chloride residue in carcass tissues is unlikely to cause toxicoses in scavengers ${ }^{3}$; however, residues of other drugs administered may pose risks. Unfortunately, there is little information available regarding tissue residues of anesthetic drugs administered immediately before euthanasia. Harms et $\mathrm{al}^{6}$ measured tissue concentrations of midazolam, acepromazine, and xylazine in mysticete whales following euthanasia and concluded that of these, only xylazine posed a potential risk of relay intoxication of scavengers. Aleman et $\mathrm{al}^{29}$ measured tissue concentrations of xylazine, midazolam, ketamine, and lidocaine in horses following euthanasia and detected levels that could cause sedation in scavengers that consumed sufficient quantities of tissue. Thus, when a carcass of a treated animal is to remain in situ, local removal of its skin, blubber, and muscle at sites of intramuscular injections may be considered to prevent scavenger intoxication and environmental contamination. ${ }^{6}$

Although the euthanasias described in the present study were performed in the controlled setting of a veterinary hospital, the procedures and techniques are readily used in a field setting. Injectable and inhalant anesthetic protocols similar to those used in the present study have also been used in field anesthesia of pinnipeds. ${ }^{20}$ Each of the pre-euthanasia anesthetic protocols used in our study resulted in a deep plane of general anesthesia for the treated animal and is considered appropriate for euthanasia with $\mathrm{KCl}$ solution.

Our suggested IC dose of $\mathrm{KCl}(250 \mathrm{mg} \mathrm{KCl} / \mathrm{kg})$ is equivalent to $0.83 \mathrm{~mL} / \mathrm{kg}(0.38 \mathrm{~mL} / \mathrm{lb})$ of a solution containing $300 \mathrm{mg} \mathrm{KCl} / \mathrm{mL}$. When the volume-based dose of this solution is rounded up to $1 \mathrm{~mL} / \mathrm{kg}(0.45$ $\mathrm{mL} / \mathrm{lb}$ ), one can estimate that $1 \mathrm{~L}$ of a solution containing $300 \mathrm{mg} \mathrm{KCl} / \mathrm{mL}$ has a sufficient amount of $\mathrm{KCl}$ for $1,000 \mathrm{~kg}$ of animal body weight. We recommend 
that a high-concentration solution of $300 \mathrm{mg} \mathrm{KCl} / \mathrm{mL}$ be used in pinnipeds instead of low-concentration (150 mg KCl/mL [ 2 mEq K $\left.\mathrm{K}^{+} / \mathrm{L}\right]$ ) pharmaceutical-grade solutions because less volume is required of a highconcentration solution. Additional considerations for field settings include human safety, environmental conditions, and appropriately prepared supplies and equipment. The potential need for and logistics of carcass identification (eg, shave markings, digit clipping, or flag or string tied around a limb) should be considered. Necropsy instruments should be available if removal of tissue surrounding IM injection sites is planned. Additionally, the ambient temperature must be considered because in cold temperatures, a precipitate may form in the $\mathrm{KCl}$ solution and physically obstruct drug delivery. ${ }^{16}$

Given our findings for representative otariid and phocid species (CSL and NES, respectively), IC or IV administration of $\mathrm{KCl}$ solution could likely be effectively used in other anesthetized species of pinnipeds. This method reduces the potential for scavenger intoxication and is appropriate for situations in which a resulting carcass cannot be retrieved for disposal. However, death by lethal injection of $\mathrm{KCl}$ in conscious or sedated vertebrates is unacceptable; general anesthesia is required for euthanasia with $\mathrm{KCl}^{3}$ Therefore, personnel administering this drug must be trained and experienced in administering anesthetic drugs and in assessing anesthetic depth in the species under care.

\section{Acknowledgments}

No third-party funding or support was received in connection with this study or the writing and publication of the manuscript. The authors declare that there were no conflicts of interests.

The authors thank Lauren Campbell, Padraig Duignan, Liz Eby, Sophie Guarasci, Barbie Halaska, Jaclyn Isbell, Kelly Miller Sarah Pattison, Deb Wickham, and Aliah Meza for their contributions to protocol development and data collection.

\section{Footnotes}

a. K-Life sodium-free water softener crystals, North American Salt Co, Overland Park, Kan.

b. Excel, version 16.46, Microsoft Corp, Redmond, Wash

c. Telazol, Zoetis Services LLC, Parsippany, NJ.

\section{References}

1. Wells K, Butterworth A, Richards N. A review of secondary pentobarbital poisoning in scavenging wildlife, companion animals and captive carnivores. J Vet Forensic Sci 2020;1:1-15.

2. Chinnadurai SK, Strahl-Heldreth D, Fiorello CV, et al. Bestpractice guidelines for field-based surgery and anesthesia of free-ranging wildlife. I. Anesthesia and analgesia. $J$ Wildl Dis 2016;52(suppl 2):S14-S27.

3. Leary S, Underwood W, Anthony R, et al. AVMA guidelines for the euthanasia of animals: 2020 edition. Schaumburg, IIl: AVMA, 2020.

4. Diercks DB, Shumaik GM, Harrigan RA, et al. Electrocardiographic manifestations: electrolyte abnormalities. J Emerg Med 2004;27:153-160.

5. Vassalle M, Greenspan K, Jomain S, et al. Effects of potassium on automaticity and conduction of canine hearts. $A m \mathrm{~J}$ Physiol 1964;207:334-340.

6. Harms CA, McLellan WA, Moore MJ, et al. Low-residue euthanasia of stranded mysticetes. $J$ Wildl Dis 2014;50:63-73.
7. Shearer JK. Euthanasia of cattle: practical considerations and application. Animals (Basel) 2018;8:1-17.

8. Cartner SC, Barlow SC, Ness TJ. Loss of cortical function in mice after decapitation, cervical dislocation, potassium chloride injection, and $\mathrm{CO}_{2}$ inhalation. Comp Med 2007;57:570-573.

9. Louis MM, Houck EL, Lewbart GA, et al. Evaluation of potassium chloride administered via three routes for euthanasia of anesthetized koi (Cyprinus carpio). J Zoo Wildl Med 2020;51:485-489.

10. Raghav R, Taylor M, Guincho M, et al. Potassium chloride as a euthanasia agent in psittacine birds: clinical aspects and consequences for histopathologic assessment. Can Vet J 2011;52:303-306.

11. Doerr M, Stoskopf MK. Evaluation of euthanasia of moon jellyfish (Aurelia aurita) using simple salt solutions. J Zoo Wildl Med 2019;50:123-126.

12. Battison A, MacMillan R, MacKenzie A, et al. Use of injectable potassium chloride for euthanasia of American lobsters (Homarus americanus). Comp Med 2000;50:545-550.

13. Bennie NAC, Loaring CD, Bennie MMG, et al. An effective method for terrestrial arthropod euthanasia. J Exp Biol 2012;215:4237-4241

14. Barco SG, Walton WJ, Harms CA, et al. Collaborative development of recommendations for euthanasia of stranded cetaceans. NOAA technical memorandum NMFS-OPR-56. Washington, DC: US Department of Commerce, 2016;1-83.

15. Daoust PY, Ortenburger AI. Successful euthanasia of a juvenile fin whale. Can Vet J 2001;42:127-129.

16. Harms CA, Greer L, Whaley J, et al. Euthanasia. In: Gulland FMD, Dierauf LA, eds. Marine mammal medicine. 3rd ed. Boca Raton, Fla: CRC Press Inc, 2018;675-691.

17. Greig DJ, Gulland FMD, Kreuder C. A decade of live California sea lion (Zalophus californianus) strandings along the Central California coast: causes and trends, 1991-2000. Aquat Mamm 2005;31:11-22.

18. LeBoeuf BJ, Laws RM eds. Elephant seals: population ecology, behavior, and physiology. Berkeley, Calif: University of California Press, 1994.

19. Le Boeuf BJ, Whiting RJ, Gantt RF. Perinatal behavior of northern elephant seal females and their young. Behaviour 1972; $43: 121-156$

20. Barbieri M. Health assessment of seals and sea lions. In: Gulland FMD, Dierauf LA, eds. Marine mammal medicine. 3rd ed. Boca Raton, Fla: CRC Press Inc, 2018;849-856.

21. Loeffler IK. Euthanasia in veterinary field projects. In: Polak KA, Kommedal T, eds. Field manual for small animal medicine. Hoboken, NJ: John Wiley \& Sons, 2018;289-306.

22. Wijdicks EFM, Varelas PN, Gronseth GS, et al. Evidencebased guideline update: determining brain death in adults. Neurology 2010;74:1911-1918.

23. Goldstein T, Mazet JAK, Zabka TS, et al. Novel symptomatology and changing epidemiology of domoic acid toxicosis in California sea lions (Zalophus californianus): an increasing risk to marine mammal health. Proc $R$ Soc B Biol Sci $2008 ; 275: 267-276$.

24. Rommel SA, Costidis AM, Lowenstine LJ. Gross and microscopic anatomy. In: Gulland FMD, Dierauf LA, eds. Marine mammal medicine. 3rd ed. Boca Raton, Fla: CRC Press Inc, 2018;90-136.

25. Gurvitch AM. Rhythmic bursts in the medullary reticular formation and their connection with agonal respiration during hypoxia and the post-hypoxic period. Electroencephalogr Clin Neurophysiol 1966;21:355-364.

26. Rea TD. Agonal respirations during cardiac arrest. Curr Opin Crit Care 2005; 11:188-191.

27. Coulibaly B, Piercecchi-Marti MD, Bartoli C, et al. Lethal injection of potassium chloride: first description of the pathological appearance of organs. J Appl Toxicol 2010;30:378-380.

28. Wetherton AR, Corey TS, Buchino JJ, et al. Fatal intravenous injection of potassium in hospitalized patients. Am J Forensic Med Pathol 2003;24:128-131.

29. Aleman M, Davis E, Knych H, et al. Drug residues after intravenous anesthesia and intrathecal lidocaine hydrochloride euthanasia in horses. J Vet Intern Med 2016;30:1322-1326. 